\title{
Didymocarpous pedicellatus R. Br.: Qualitative and Quantitative GCMS Approach for Quality Control in Traditional Poly-herbal Formulation with In vitro Antioxidant and Antimicrobial Activity
}

\author{
WASIM AHMAD 1 , ENNUS T. TAMBOLI ${ }^{2}$, ABUZER ALI ${ }^{3}$, MOHD. AMIR $^{4}$, \\ S. M. A. ZAIDI ${ }^{5}$ and SAYEED AHMAD ${ }^{2}$
}

${ }^{1}$ Mohammad Al-Mana College for Health Sciences, Department of Pharmacy, Dammam, Dammam 34222, Kindom of Saudi Arabia.

${ }^{2}$ Bioactive Natural Product Laboratory, Department of Pharmacognosy and Phytochemistry, Faculty of Pharmacy, Jamia Hamdard (Hamdard University), New Delhi - 110062, India.

${ }^{3}$ Department of Pharmacognosy, College of Pharmacy, Taif University, Haweiah, Taif-21974,

Kindom of Saudi Arabia.

${ }^{4}$ Department of Natural Products and Alternative Medicine, College of Clinical Pharmacy,

University of Dammam, Dammam-34222, Kindom of Saudi Arabia.

${ }^{5}$ Department of Surgery, Faculty of Medicine, Jamia Hamdard (Hamdard University), New Delhi-110062, India. ${ }^{*}$ Corresponding author E-mail: sahmad_jh @yahoo.co.in

http://dx.doi.org/10.13005/ojc/350220

(Received: October 20, 2018; Accepted: April 07, 2019)

\begin{abstract}
S
A Gas Chromatography and Maas Spectroscopy method was developed and validated for determination and identification of $\alpha$-humulene in a traditional medicinal herb Didymocarpous pedicellatus R. Br. (DP) (Gesneriaceae) and its poly herbal formulation, Safoof-e-pathar phori (SPP) including their essential oil. Hydrodistillation method were used for the isolation of essential oils from the leaves of DP and SPP herbal formulation. The proposed analysis method was found to be linear $\mathrm{r}^{2}=0.999$ in a wide concentration range $\left(0.1-1000 \mu \mathrm{gmL}^{-1}\right)$, with good precision (RSD $\left.<2.0 \%\right)$. Antimicrobial activity of $\alpha$-humulene, DP and SPP oil was assessed by using agar well diffusion method against clinically important Gram-positive, Gram-negative bacteria and fungi. $\alpha$-Humulene was found to be more active in contrast to Gram-negative bacteria while DP oil and SPP oil were exhibited maximum inhibition against fungal strains. Antioxidant activity of $\alpha$-humulene, DP oil and SPP oil were determined using 2, 2-diphenyl-1-picryl hydrazyl radical (DPPH) 96 well plate method, which showed antioxidant activity in the following order: standard ascorbic acid (DPPH FRS $\left.{ }_{50}=2.40 \mu \mathrm{g}\right)>$ DP oil $($ DPPH FRS50 $=3.68 \mu \mathrm{g})>$ SPP oil $($ DPPH FRS50 $=12.54 \mu \mathrm{g})>$ and $\alpha$-humulene $($ DPPH $\mathrm{FRS50}=36.19 \mu \mathrm{g})$.
\end{abstract}

Keywords: Didymocarpous pedicellatus, Safoof-e-Pathar phori, $\alpha$-humulene, GC-MS, Essential oil

This is an Open Access article licensed under a Creative Commons license: Attribution 4.0 International (CC- BY). Published by Oriental Scientific Publishing Company @ 2018 


\section{INTRODUCTION}

Natural antioxidant obtained from plants, particularly the phenolic and flavonoids carry high nutraceutical value ${ }^{1}$. These compounds have also shown different pharmacological activities and offer beneficial effects on health primarily due to free radical scavenging properties ${ }^{2}$. Number of medicinal plants produces these antioxidants as secondary metabolites ${ }^{3}$. Thus, there is increasing attention in growing many plant-derived drugs with various biological functions for the treatment of several infectious diseases. These antioxidants especially phenolic acids can also inhibit pathogens growth with nominal toxicity, thus, offering promising potential for development of antimicrobial agents $\mathrm{s}^{4,5}$.

Didymocarpous pedicellatus R. Br. (DP) (Gesneriaceae) is an important endangered medicinal plant, commonly known as Pathar phori. Traditionally, it acts as diuretic, lithotriptic, nephroprotective and for cleansing of bladder-8. The drug has been recommended and used for stones in kidney and bladder, renal colic, burning micturation, diabetes, diarrhoea, chest pain, cough, epilepsy, heart diseases, stomachache, splenitis, syphilis, wound and ulcers ${ }^{9}$. Chemically the plant contains chalcones, flavones, polyterpenes and Essential oil. Essential oil has been reported for antimicrobial activity ${ }^{10}$.

Safoof-e-Pathar phori (SPP) is a traditional polyherbo-mineral formulation used for its anti-urolithiatic activity in traditional system of medicine since long time ${ }^{11}$. SPP is a powdered formulation, containing six different constituents. Plant constituents: Patharphori (D. pedicellatus) ${ }^{12}$, kulthi (Dolichous biflorus) ${ }^{13}$, revand chini (Rheum emodi) ${ }^{14}$ and mineral constituents: shoraqalmi (Potassium nitrate), namak turb (Raphanus sativus) and jawakhar (Potassium carbonate) ${ }^{15}$.

GC-MS has one of the most commonly used technique for the identification and quantitative analysis of volatile components in traditional herbal medicines including polyherbal formulations containing essential oil, due to the high specificity and sensitivity. GC-MS was used for both qualitative and quantitative analysis of $\alpha$-humulene. Very few reports are available about quantitative estimation of humulene in polyherbal formulation and no work is available about quality control evaluation of a polyherbal formulation by defining $\alpha$-humulene quantity. In the present study a new GC-MS method has been developed for quantitative estimation of humulene in $D$. pedicellatus and in traditional poly herbal formulation.

The use of $D$. pedicellatus, in several lithotriptic formulation of Indian system of medicine encouraged us to come out its chromatographic analysis for scientific validation. Due to its extensive therapeutic significance and rare availability, it was thought worthwhile to develop its chromatographic fingerprints, which could be useful for its quality control/standardization, identification and authentication as well as for checking its genuinty among adulterated samples ${ }^{16}$. There are no analytical methods reported for quantitative estimation of any marker constituents of $D$. pedicellatus till date.

In the present study quantitative estimation of $\alpha$-humulene in hexane extracts of $D$. pedicellatus, SPP and their hydro-distilled oils was carried out for the first time by GCMS. In addition to GCMS method for quality control, antimicrobial and antioxidant activities of hydro-distilled oils of $D$. pedicellatus, SPP and $\alpha$-humulene were also carried out.

\section{EXPERIMENTAL}

\section{MATERIAL AND CHEMICALS}

Standard Alpha-humulene, DPPH and L-ascorbic acid, were purchased from Sigma Aldrich (USA). HPLC grade solvents were obtained from (Merck, Mumbai, India). Membrane filters $(0.45 \mu \mathrm{m})$ used for filteration was purchased from Millipore, Germany.

\section{Plant material and sample preparation}

The leaves of $D$. pedicellatus were collected from Khari Baoli, local market of New Delhi and authenticated by Dr. H. B. Singh, Head, Ref. NISCAIR/RHMD/1327/129, New Delhi. The leaves were dried and powdered in an electric grinder. The powdered leaves of $D$. pedicellatus and SPP were used for the extraction of $\alpha$-humulene.

The powdered $D$. pedicellatus and SPP powder ( $1.0 \mathrm{~g}$ each) were extracted separately, with $15 \mathrm{~mL}$ of hexane by sonication for $30 \mathrm{~min}$ at $45^{\circ} \mathrm{C}$. The process was repeated twice to ensure complete 
extraction. The extracts obtained were pooled and dried under reduced pressure. The residue obtained from each extract was redissolved separately in $25 \mathrm{~mL}$ of HPLC grade hexane and subjected to GC-MS analysis for quantitative determination of $\alpha$-humulene.

All samples were filtered through a $0.45 \mu \mathrm{m}$ nylon membrane filter before use.

\section{Isolation of essential oil}

The dried leaves of $D$. pedicellatus were crushed and powdered SPP oil was isolated using Clevenger apparatus by hydro-distillation method. The percentage yield of D. pedicellatus oil was found to be $1.25 \%$ light yellow color and SPP oil was $0.75 \%$ dark yellow colour.

\section{GC-MS instrumentation and chromatographic conditions for qualitative estimation}

Qualitative analysis of essential oil was performed by GC-MS using Agilent 7890A GC system have automatic sampler CTC analysis CombiPAL robotic arm, equipped with MS detector 5975C inert XL EI/CI MSD. For GC/MS detection, an electron ionization system with ionization energy of $70 \mathrm{eV}$ was used. HP-5MS Agilent Phenyl Methyl Silox (30 m length X0.25 ID mm, $0.25 \mu \mathrm{m}$ ) capillary column used. The injector was worked in split mode (50: 1) and the injection volume was $2.0 \mu \mathrm{L}$. The inlet temperature was kept at $270^{\circ} \mathrm{C}$ with helium flow rate at $1.0 \mathrm{~mL} \mathrm{~min}^{-1}$. The

The oven temperature was initially $80^{\circ} \mathrm{C}$ for $2 \mathrm{~min}$ then increased to $300^{\circ} \mathrm{C}$ with total run time of $36 \mathrm{~min}$ at SCAN mode.

The GC-MS analysis of essential oil was performed using Agilent 7890A GC system equipped with $\mathrm{MS}$ detector $5975 \mathrm{C}$ inert $\mathrm{XL} \mathrm{EI} / \mathrm{Cl}$ MSD automatic sampler CTC analysis CombiPAL robotic arm. For GC/MS detection, an electron ionization system with ionization energy of $70 \mathrm{eV}$ was used. The specification of capillary column used was Agilent Phenyl Methyl Silox (30 m length X0.25 ID mm, $0.25 \mu \mathrm{m}) \mathrm{HP}-5 \mathrm{MS}$. The injector was operated in split mode (50: 1) and the injection volume was $2.0 \mu \mathrm{L}$. The inlet temperature was kept at $270^{\circ} \mathrm{C}$ with helium flow rate at $1.0 \mathrm{~mL} \mathrm{~min}^{-1}$. The oven temperature was initially $80^{\circ} \mathrm{C}$ for $2 \mathrm{~min}$ then increased to $300^{\circ} \mathrm{C}$ with total run time of $36 \mathrm{~min}$ at SCAN mode.
The components of oils were identified from the mass value by comparing it through Nist/Wiley library installed with equipment.

\section{GC-MS instrumentation and chromatographic conditions - Quantitative estimation}

The GC-MS condition for the analysis of $\alpha$-humulene was similar to the qualitative estimation. The oven temperature was initially $80^{\circ} \mathrm{C}$ for $2 \mathrm{~min}$ then increased to $300^{\circ} \mathrm{C}$ at a rate of $10^{\circ} \mathrm{C}$ and hold for 10 min with total run time of 34 min at SCAN mode.

\section{Method validation}

The developed GC-MS method was validated as per the $\mathrm{ICH}$ guideline ${ }^{17}$ for selectivity, linearity, limits of detection (LOD \& LOQ) and quantification, precision and accuracy.

\section{In vitro antimicrobial activity}

The antimicrobial potential of $\alpha$-humulene, DP and SPP oil were tested against Bacillus subtilis (MTCC 2756) which is a Gram-positive strain and Escherichia coli (MTCC 1652) which is a Gramnegative strain. Both the strains of bacteria were procured from Microbiology Department, Institute of Microbial Technology, Chandigarh, India. Pathogenic fungi Rhizopus oryzaeand Penicillium chrysogenumwere obtained microbial and pharmaceutical biotechnology laboratory, New Delhi, India. Nutrient agar medium was used to maintain all the bacterial cultures while fungal cultures were maintained on potato dextrose agar medium at $4^{\circ} \mathrm{C}$. Dimethyl sulphoxide (DMSO) was used as solvent to prepare standard solutions of ampicilline and fluconazole $\left(50 \mu \mathrm{g} \mathrm{mL}^{-1}\right)$.

\section{Preparation of test organisms}

Bacterial strains were preserved on slants of nutrient agar medium and fungal cultures were on potato dextrose agar medium. Both bacterial and fungal cultures once in a month transferred to a freshly prepared slant and incubated at $37^{\circ} \mathrm{C}$ for 24 hours and $25^{\circ} \mathrm{C}$ for $72 \mathrm{~h}$ respectively. The mycelium or cells were washed from the slants by using sterilized normal saline $(10 \mathrm{~mL})$. The quantity of suspension to be added to each agar or nutrient broth $(100 \mathrm{~mL})$ was decided by use of test plates. Further, the strains were kept under refrigeration for storage.

\section{Anti-microbial assay}

In vitro antimicrobial activity was performed by agar well diffusion method ${ }^{18}$. Each sterilized, 
liquified nutrient agar medium $(50 \mathrm{~mL})$ and potato dextrose agar medium (50 $\mathrm{mL})$ was transferred into petri-plates (145 $\mathrm{mm}$ size) and set aside for solidifying. Each bacterial and fungal suspensions were spread over the solidified media. A sterilized stainless steel borer was used to made bores $(6 \mathrm{~mm}$ ID) in each plate. Dilutions of each $\alpha$-humulene, DP oil and SPP oil were made in DMSO having concentration of $50 \mathrm{\mu gmL}^{-1}$ and $100 \mathrm{\mu gmL}^{-1}$. Ampicilline $\left(50 \mu \mathrm{g} \mathrm{mL}^{-1}\right)$ and fluconazole $\left(50 \mu \mathrm{g} \mathrm{mL}^{-1}\right)$ solutions were used as standards. After application of drugs/test solutions, the petri-plates were kept for $3 \mathrm{~h}$ at $4^{\circ} \mathrm{C}$ for proper diffusion. Further, the plates were incubated for bacterial culture at $37^{\circ} \mathrm{C}$ for 24 hours. After $24 \mathrm{~h}$, the plates were examined, and the zones of inhibition was accurately measured. The petri-plates inoculated with fungi were incubated at $25^{\circ} \mathrm{C}$ for 72 hours and the zones of inhibition was accurately measured by zone reader.

\section{In vitro antioxidant activity \\ 2, 2-diphenyl-1-picryl hydrazyl (DPPH) assay}

The free radical scavenging potential of each $\alpha$-humulene, DP oil and SPP oil were assessed by the method reported by Blois (1998), with slight modifications ${ }^{15,19}$. Each sample was dissolved in methanol. $0.5 \mathrm{mM}$ DPPH $(100 \mu \mathrm{L})$ was added and mixed properly with samples $(100 \mu \mathrm{L})$ in 96 well plate at various concentrations $(3.906,7.812$, $15.625,31.25,62.5,125.0,250.0$ and $500.0 \mu \mathrm{g}$ for $\alpha$-humulene; 1.56, 3.12, 6.25, 12.5, 25.0, 50.0, 100.0 and $200 \mu \mathrm{g}$ for SPP oil; $0.781,1.56,3.12,6.25$, $12.5,25.0,50.0$ and $100.0 \mu \mathrm{g}$ for DP oil and ascorbic acid) in triplicate. Further, the plate was kept in dark at room temperature for 30 minutes. The control solution was without sample or standard, whereas blank solution was DPPH in methanol without sample. The absorbance of all the concentrations of samples and standards were measured in Elisa plate reader (Bio Rad 680) at 540 nm. Graph Pad Prism software version 5 was used for dose response curve.

Free radical scavenging activity was measured using the corrected ODs (COD) of control and samples as per the below mentioned formula:

COD control = OD control - OD control blank

Free radical scavenging activity $(\%)=$ COD control - COD sample / COD control X 100

\section{RESULTS}

\section{Qualitative characterization of $\boldsymbol{D}$. pedicellatus}

The GC-MS analysis of hydro-distilled oil of $D$. pedicellatus led to the identification and quantification of twenty six components (Fig. 1). Components with their percentage are tabulated in table I. hydro-distilled oil of $D$. pedicellatus was characterized by large numbers of sesquiterpenes (97.94\%) and less concentration of monoterpenes $(1.09 \%)$, all were positively characterized. Among fourteen sesquiterpenes, there were eleven sesquiterpene hydrocarbons (96.90\%), namely $\alpha$-humulene $(71.97 \%)$, isoseychellene $(9.95 \%)$, $\beta$-gurjunene $(4.29 \%), \beta$-Selinene $(3.80 \%)$, $\alpha$-panasinsen (3.29\%), aromadendrene (1.04\%), selina-4,11-diene $(0.85 \%)$, caryophyllene $(0.83 \%)$, $\beta$-bisabolene $(0.33 \%)$, longifolene $(0.24 \%)$, eudesma$4(14), 11$-diene $(0.21 \%)$ and $\alpha$-guaiene $(0.10 \%)$, There were two sesquiterpene alcohols identified as 1,5,5,8-tetramethyl-3,7-cycloundecadien-1-ol $(0.42 \%)$ and 5 -epi-neointermedeol $(0.31 \%)$ along with a sesquiterpene oxide as humulene 1,2epoxide $(0.31 \%)$. Monoterpenes were consist of camphene $(0.37 \%)$ and limonene $(0.27 \%)$, and two monoterpenes alcohols namely, $\alpha$-terpineol $(0.09 \%)$ and linalool $(0.07 \%)$ along with an ester of monoterpenes alcohol, lavandulyl acetate $(0.06 \%)$. A monoterpenes phenol was characterized as phenol, 5-methyl-2-(1-methylethyl) (0.23\%). Other components were identified as a ketone, namely amyl ethyl ketone $(0.09 \%)$ and two cycloalkane characterized as cyclohexene, 3-(2-propenyl) $(0.12 \%)$ and 3 -methylenecycloheptene $(0.05 \%)$.

\section{Quantitative estimation of $\alpha$-humulene}

Quantitative estimation of $\alpha$-humulene in D. pedicellatus and traditional polyherbal formulations

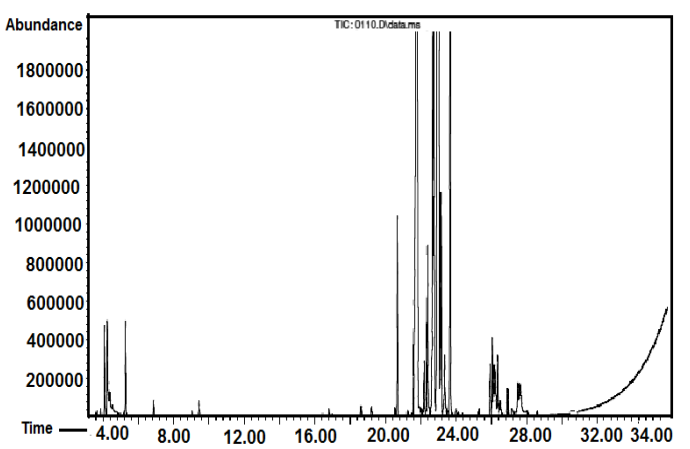

Fig. 1. GC-MS chromatogram of $D$. pedicellatus oil of qualitative estimation 
Table 1: Chemical composition of $D$. pedicellatus oil

\begin{tabular}{lcc}
\hline Compound & Retention Time & $\%$ of Total \\
\hline Benzaldehyde & 4.059 & $0.31 \%$ \\
1 octen 3 ol & 4.239 & $0.41 \%$ \\
Amyl ethyl ketone & 4.368 & $0.09 \%$ \\
Limonene & 5.250 & $0.27 \%$ \\
Linalool & 6.858 & $0.07 \%$ \\
$\alpha$-terpineol & 9.421 & $0.09 \%$ \\
Phenol, 5-methyl-2-(1-methylethyl) & 17.309 & $0.23 \%$ \\
3-Methylenecycloheptene & 18.545 & $0.05 \%$ \\
Beta.bisabolene & 19.045 & $0.33 \%$ \\
Caryophyllene & 20.756 & $0.83 \%$ \\
Lavandulyl acetate & 21.746 & $0.06 \%$ \\
Alpha panasinsen & 21.867 & $3.29 \%$ \\
Longifolene & 22.378 & $0.24 \%$ \\
Aromadendrene & 22.528 & $1.04 \%$ \\
Selina-4,11-diene & 22.825 & $0.85 \%$ \\
$\alpha$-caryophyllene/ $\alpha$-humulene & 23.528 & $71.97 \%$ \\
$\beta$-gurjunene & 23.616 & $4.29 \%$ \\
Beta.-selinene & 23.771 & $3.80 \%$ \\
Isoseychellene & 23.942 & $9.95 \%$ \\
$\alpha-g u a i e n e$ & 24.105 & $0.10 \%$ \\
Camphene & 25.982 & $0.37 \%$ \\
3,7-Cycloundecadien-1-ol, & 26.061 & $0.42 \%$ \\
Humulene 1,2-epoxide & 26.644 & $0.31 \%$ \\
Cyclohexene,3-(2-propenyl) & 27.310 & $0.12 \%$ \\
Eudesma-4(14),11-diene & 27.882 & $0.21 \%$ \\
5-Epi-NeointermedeolLedene & 28.297 & $0.31 \%$ \\
Total components of oil & & $100 \%$ \\
\hline
\end{tabular}

has been carried out for the first time as per previous reports there is no quantitative estimation method is available till date for humulene in $D$. pedicellatus in till date. The current study was designed to develop a simple and reliable GC-MS method for well separation and estimation of $\alpha$-humulene in $D$. pedicellatus, polyherbal formulation and hydro-distilled oil. The retention time of standard $\alpha$-humulene was 23.564 min (Fig. 2). The similar conditions were followed in the crude hexane extract of leaves of $D$. pedicellatus, SPP and their hydro-distilled oils for the separation of $\alpha$-humulene. (Figure 3 and 4).

\section{Validation of GC-MS method}

The developed GC-MS method was validated as per ICH guidelines for selectivity, linearity, limits of detection and quantification, precision and accuracy as detailed below.

\section{Selectivity}

From the chromatogram shown in Fig. 2, it is marked, that under the selected chromatographic conditions, $\alpha$-humulene were completely separated, which showed that the method is selective and could be used for their identification and quantitative analysis. Retention time of analyte was 23.564 . The specificity of the GC method was confirmed by injecting blank sample. No other peaks were observed at the retention time of $\alpha$-humulene, indicating that interfering substances were not present.

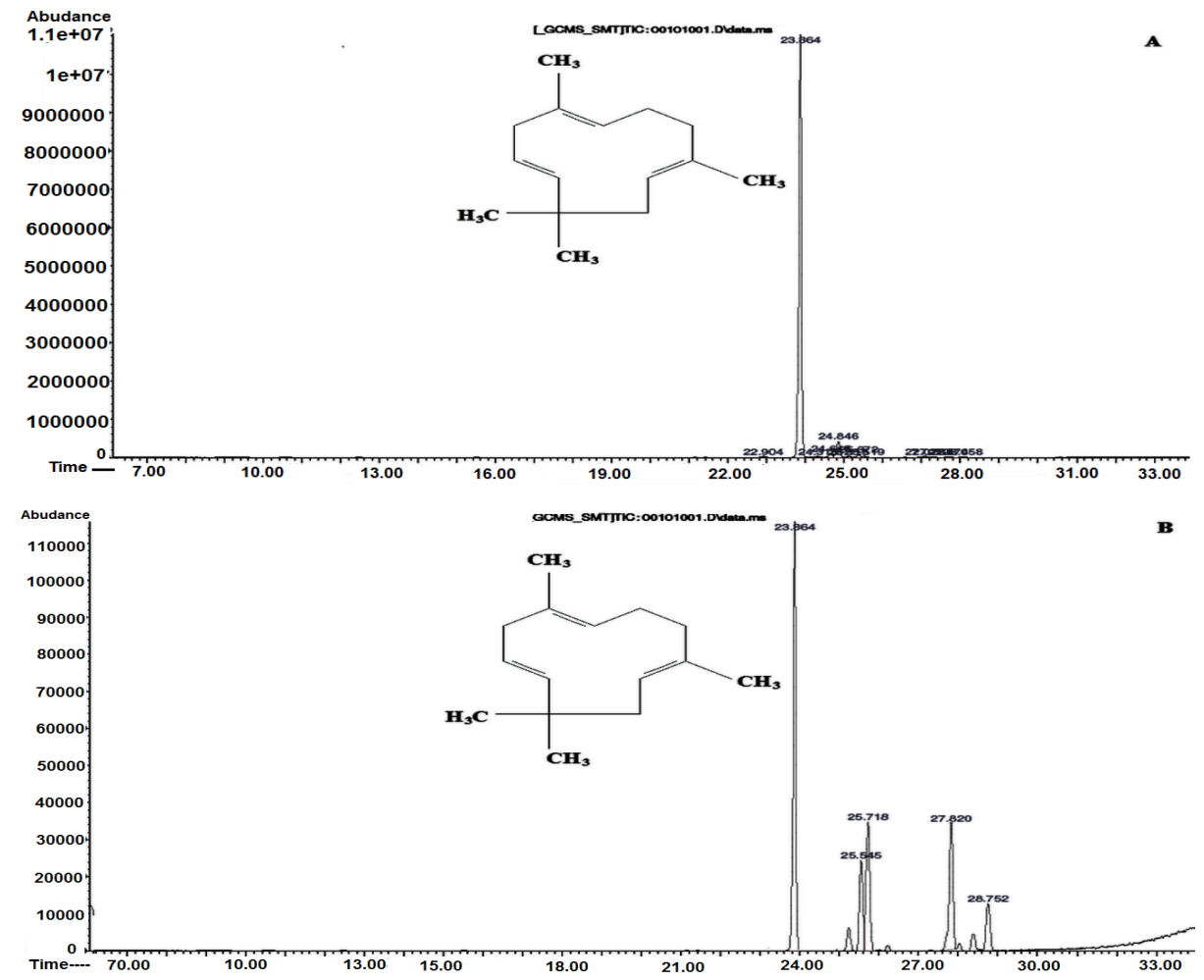

Fig. 2. GC-MS chromatogram (A) standard $\alpha$-humulene (B) MS spectrum of $\alpha$-humulene scan mode (C) MS spectrum of $\alpha$-humulene provided by NIST library 


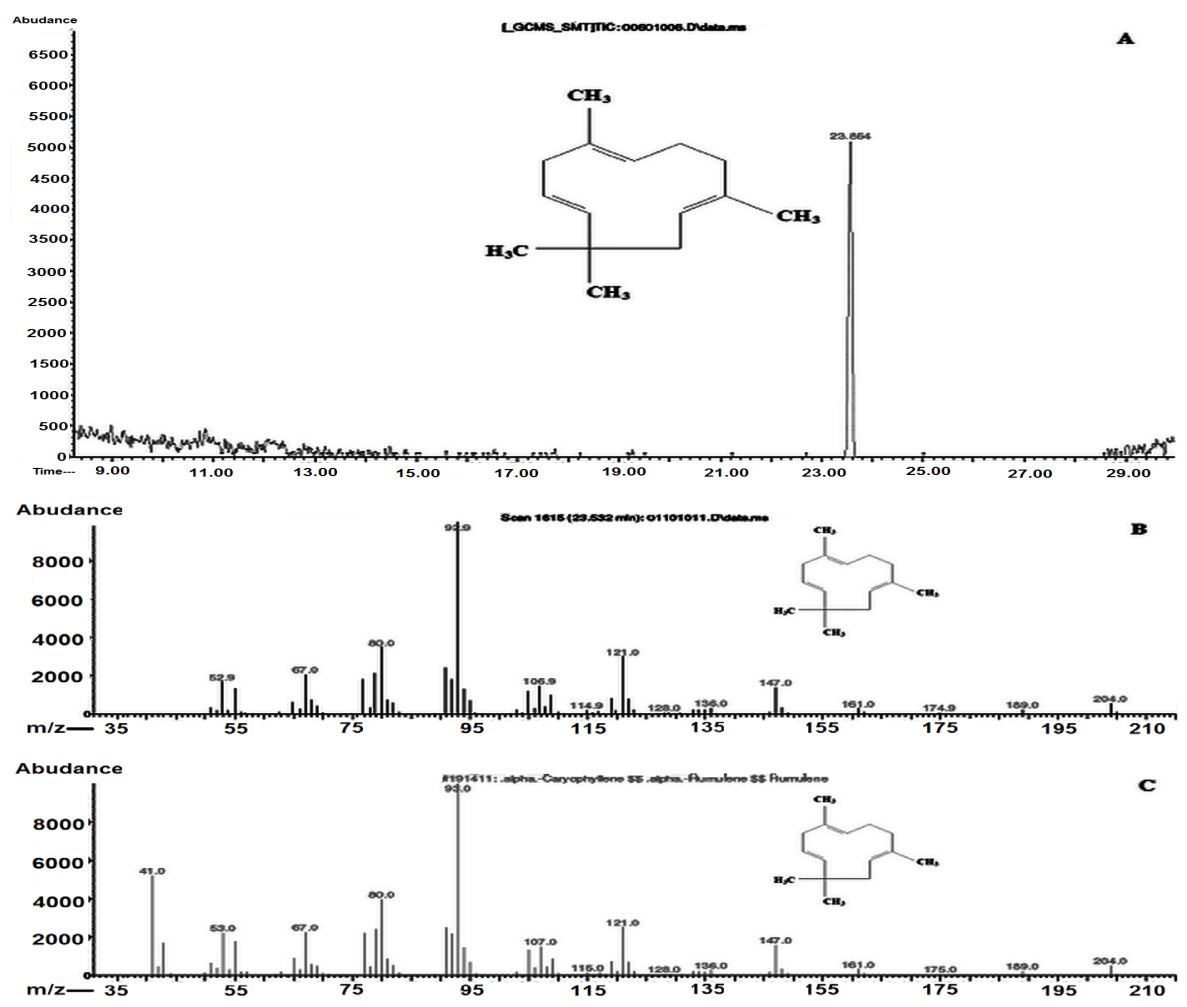

Fig. 3. GC-MS chromatogram of (A) D. pedicellatus oil, (B) D. pedicellatus hexane extract
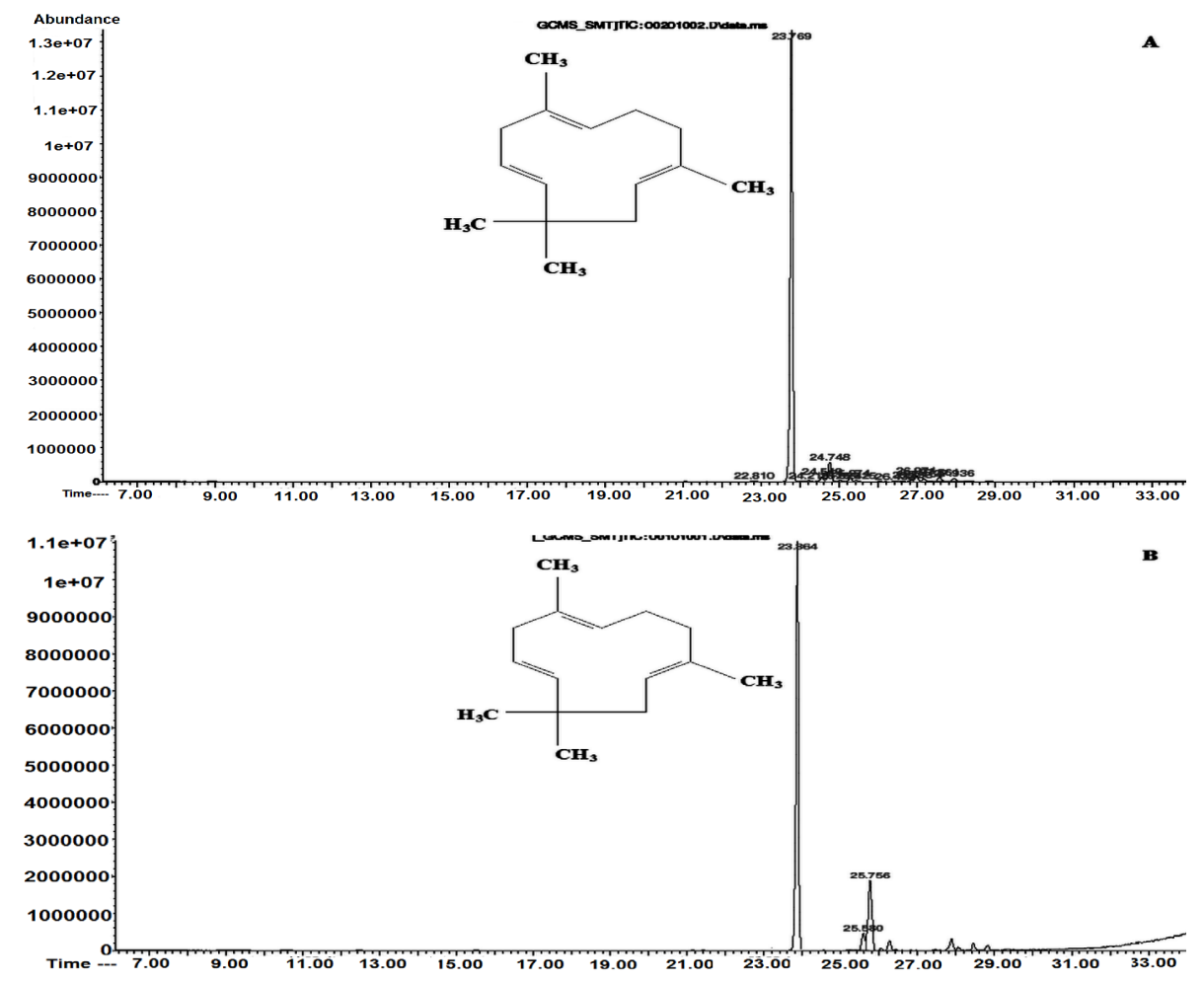

Fig. 4. GC-MS chromatogram of (A) Safoof-e-Pathar phori oil, (B) Safoof-e-Pathar phori hexane extract 


\section{Linearity}

Linearity was assessed at ten concentration levels ranging from $0.1-1000 \mu \mathrm{g} \mathrm{mL}^{-1}$, having correlation coefficient of 0.9999 . The LOD and LOQ were found as 0.03 and $0.1 \mathrm{\mu g} \mathrm{mL}^{-1}$ for $\alpha$-humulene (Table II).

Table 2: Linearity and limits of detection and quantification of $\alpha$-humulene

\begin{tabular}{cc}
\hline Parametrs & $\alpha$-humulene \\
\hline Regression equation & $\mathrm{Y}=25953 \mathrm{x}+12815$ \\
Linear range & $1-1000 \mu \mathrm{gl}^{-1}$ \\
Correlation coefficient $(\mathrm{r})$ & 0.999 \\
LOD & $0.03 \mu \mathrm{g} / \mathrm{ml}^{-1}$ \\
LOQ & $0.1 \mu \mathrm{g} \mathrm{ml}^{-1}$ \\
\hline
\end{tabular}

\section{Precision}

The precision of the method was carried out by performing six different concentrations of the test sample preparation and calculating RSD (\%). The RSD values measured during evaluation of precision were $<2.0 \%$ for $\alpha$-humulene, confirming the method is precise. The results of precision of the method are presented in Table III which was found in acceptable range.

Table 3: Precision (\% RSD) of $\alpha$-humulene

\begin{tabular}{cc}
\hline Precision & $\alpha$-humulene (\% RSD) \\
\hline Intra-day $(\mathrm{n}=5)$ & 1.85 \\
& 0.66 \\
& 1.94 \\
Inter-day $(\mathrm{n}=5)$ & 1.42 \\
& 0.48 \\
& 1.25 \\
\hline
\end{tabular}

\section{Accuracy as recovery}

The accuracy of the methods, evaluated as \%recovery by addition of low, medium and high concentrations of $\alpha$-humulene (Table IV). The recovery results showed between ranging from 98 to $104 \%$.

Table 4: Accuracy of $\alpha$-humulene

\begin{tabular}{ccc}
\hline $\begin{array}{c}\text { Excess spike (\%) } \\
\text { concentration added }\end{array}$ & \% recovery of $\alpha$-humulene & \% RSD \\
\hline 50 & $98.15 \pm 0.11$ & 1.22 \\
100 & $101.28 \pm 0.70$ & 0.83 \\
150 & $104.08 \pm 1.07$ & 0.61 \\
\hline
\end{tabular}

Analysis of $\alpha$-humulene in hexane extracts of polyherbal formulation, leaves of $D$. pedicellatus and their hydro-distilled oils.

Hexane extract of SPP and leaves of $D$. pedicellatus were analysed by GC-MS method for amount of $\alpha$-humulene. GC-MS chromatogram of standard $\alpha$-humulene given in Fig. 2 . The analysis of $\alpha$-humulene in SPP hexane extract showed 3.34 $\mathrm{g} \mathrm{kg}^{-1}$ where SPP oil showed $332.28 \mathrm{~g} \mathrm{~L}^{-1}$.

Similarly, concentration of $\alpha$-humulene in $D$. pedicellatus hexane extract was observed $7.627 \mathrm{~g} \mathrm{~kg}^{-1}$ whereas $D$. pedicellatus oil showed $509.40 \mathrm{~g} \mathrm{~L}^{-1}$ for the satisfactory analysis of this constituent in SPP.

\section{In vitro Antimicrobial activity}

The antimicrobial activity of the $\alpha$-humulene, D. pedicellatus and SPP oil were evaluated against clinically significant bacterial strains comprising both Gram-positive and Gram-negative, and antifungal activity against $R$. oryzae and $P$. chrysogenum, and their effectiveness was assessed qualitatively and quantitatively by the presence or absence of inhibition zones and their diameters. The results are given in Table $V$ which indicates that the $\alpha$-humulene showed a broad spectrum and variable degree of antibacterial and antifungal activity against the different tried strains as compared to standard, ampicillin and fluconazole, respectively. When tested by agar diffusion method the results obtained in the study showed that $\alpha$-humulene showed activity against all the tested strains. Higher concentration of $\alpha$-humulene $\left(100 \mathrm{\mu gmL}^{-1}\right)$ obtained maximum activity against E. coli (19 mm), P. chrysogenum (19 mm), $B$. subtilis $(18 \mathrm{~mm})$ and $R$. oryzae $(18 \mathrm{~mm})$ when compared to ampicillin $\left(50 \mu \mathrm{gmL}^{-1}\right)$. $\alpha$-Humulene (50 $\mathrm{\mu gmL}^{-1}$ ) showed potent activity against $P$. chrysogenum $(16 \mathrm{~mm})$ and $E$. coli $(15 \mathrm{~mm})$. The DPO $\left(100 \mu \mathrm{gmL}^{-1}\right)$ exhibited better activity against fungal strains, $P$. chrysogenum $(20 \mathrm{~mm})$ and R. oryzae $(18 \mathrm{~mm})$ than bacterial strains, E. coli $(14$ $\mathrm{mm})$ and $B$. subtilis $(10 \mathrm{~mm})$. SPP oil $\left(100 \mu \mathrm{gmL}^{-1}\right)$ showed maximum inhibition against $P$. chrysogenum $(20 \mathrm{~mm})$ and $R$. oryzae $(19 \mathrm{~mm})$ while exhibited moderate activity against $B$. subtilis $(12 \mathrm{~mm})$ when compared to fluconazole $\left(50 \mathrm{\mu gmL}^{-1}\right)$.

\section{In vitro Antioxidant activity}

Antioxidant activity of $\alpha$-humulene, D.pedicellatusoil and SPP oil were determined using 2, 2-diphenyl-1-picryl hydrazyl radical (DPPH) 96 well plate method. The DPPH FRS ${ }_{50}$ values were evaluated by dose response curve (\% inhibition vs log dose) (Fig. 5) which showed antioxidant potential 
of standard ascorbic acid (DPPH FRS50 $=2.40 \mu \mathrm{g}$ ), D. pedicellatusoil $\left(\mathrm{DPPH} \mathrm{FRS}_{50}=3.68 \mu \mathrm{g}\right)$ and SPP oil (DPPH FRS $\left.{ }_{50}=12.54 \mu \mathrm{g}\right)$ while $\alpha$-humulene (DPPH FRS50 $=36.19 \mu \mathrm{g}$ ) showed less scavenging effect.

Table 5: Antimicrobial activity of the alpha humulene, D. pedicellatus oil and SPP oil on tested pathogenic microbes

\begin{tabular}{lcccc}
\hline $\begin{array}{l}\text { Test drugs/standard } \\
\text { concentration }\end{array}$ & \multicolumn{2}{c}{ Drugs Zone of inhibition to pathogenic fungi/ bacterial strains (mm) } \\
& B. subtilis & E. coli & P. chyrosogenum & R. oryzae \\
\hline$\alpha$-humulene $50 \mu \mathrm{gmL}^{-1}$ & 13 & 15 & 16 & 14 \\
$\alpha$-humulene $100 \mu \mathrm{gmL}^{-1}$ & 18 & 19 & 19 & 18 \\
DPO $50 \mu \mathrm{gLL}^{-1}$ & 8 & 10 & 19 & 15 \\
DPO $100 \mu \mathrm{gmL}^{-1}$ & 10 & 14 & 20 & 18 \\
SPPO $50 \mu \mathrm{gmL}^{-1}$ & 8 & 6 & 19 & 17 \\
SPPO $100 \mu \mathrm{gmL}^{-1}$ & 12 & 8 & 20 & 19 \\
Ampicillin $50 \mathrm{mgmL}^{-1}$ & 11 & 10 & -- & -- \\
Fluconazole $50 \mu \mathrm{gmL}^{-1}$ & -- & -- & 16 & 17 \\
\hline
\end{tabular}

DPO - Didymocarpous pedicellatus oil, SPPO - Safoof-e-Pathar phori oil

\section{DISCUSSION}

Based on the current literature survey, there is no any method has been reported for qualitative and quantitative analysis of $\alpha$-humulene in $D$. pedicellatus. The essential oil composition of $D$. pedicellatus has no previous records; the outcomes presented here are the first evidence with the detection of a monocyclic sesquiterpens, $\alpha$-humulene $(71.97 \%)$ in high percentage with other components (Table I) of this unique and endangered species. GC-MS is a widely used technique for the estimation of volatile constituents in essential oils and herbal drug extracts. In the present investigation a validated GC-MS method for the estimation of $\alpha$-humulene in hexane extracts of SPP, leaves of $D$. pedicellatus and their hydro-distilled oils were optimized. The peaks corresponding to $\alpha$-humulene in samples were identified by comparing retention time (23.564 min) and mass spectra, $204\left[\mathrm{M}^{+}\right]$. This method was found sensitive enough to monitor the lower concentrations of $\alpha$-humulene in the samples. $\alpha$-Humulene has various biological significances ${ }^{20}$, and measured as a chemical marker for the standardization of traditional polyherbal formulations containing $D$. pedicellatus leaves. In traditional system of medicine, Safoof-e-Pathar phori has been used for anti-urolithiatic activity (11), and several study supports the presence of humulene in herbal medicine used for anti-urolithiatic activity ${ }^{21}$. In this context, our study also support the anti urolithiatic activity of polyherbal formulation by confirming the presence humulene content and other metabolites of essentials oils. Traditional formulations often contain a huge number of herbs using varying quantities and are prepared by traditional methods. In this study, one frequently used polyherbal formulation, namely 'Safoof-e-Pathar phori' containing D. pedicellatus leaves was selected and the amount of $\alpha$-humulene was evaluated. The amount of $\alpha$-humulene in SPP hexane extract was $3.34 \mathrm{~g} \mathrm{~kg}^{-1}$ where SPP oil showed $332.28 \mathrm{~g} \mathrm{~L}^{-1}$.
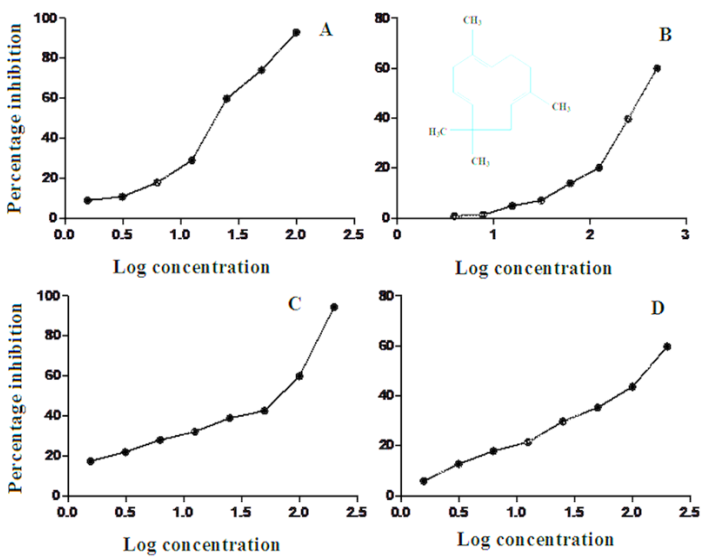

Fig. 5. Scavenging effect on 2, 2-diphenyl-1-picryl hydrazyl radical evident from dose response curve Standard ascorbic acid (A) $\alpha$-humulene (B) D. pedicellatus oil (C) and Safoof-ePathar phori oil (D)

The antibacterial activity of the $\alpha$-humulene, $D$. pedicellatus and SPP oil were determined against both bacterial and antifungal strains. In the present observations, $\alpha$-humulene showed potent antimicrobial activity against Gram-positive, B. subtilis and Gram-negative, E. coli bacteria, and $P$. chrysogenum and $R$. oryzae fungus. The $D$. pedicellatus and SPP oils in different concentrations 
showed better activity against $P$. chrysogenum and $R$. oryzae than $B$. subtilis and $E$. coli. The study suggested that the $D$. pedicellatus and SPP oils are more potent against fungal strains while $\alpha$-humulene was effective for both fungal and bacterial strains. Antimicrobial activity of $D$. pedicellatus and SPP oil could be attributed to the presence of high percentage of sesquiterpenes (97.94\%) and these research findings are in agreement with the previous reports ${ }^{22}$.

D. pedicellatus hydro-distilled oil contains $\alpha$-humulene as major component which is a monocyclic sesquiterpene. $\alpha$-Humulene showed potent antimicrobial activity as compare to standards and hydro-distilled oils. The antimicrobial activity of individual component, $\alpha$-humulene has been reported previously ${ }^{23}$. The observed difference in the antibacterial activity of the agents in contrast to each culture may be due to structural difference between the microorganisms ${ }^{24,25}$.

The effect of antioxidants on DPPH is supposed to be due to their hydrogen contributing capability. The use of the DPPH free radical scavenging assay is valuable in assessing antioxidant efficiency because the DPPH radical is more stable than hydroxyl or superoxide radicals. DPPH is an established radical that loses its colour when it receives an electron from an antioxidant molecule. The DPPH antioxidant potential of $\alpha$-humulene, DP and SPP oil were carried out in different concentrations with reference to standard ascorbic acid. The antioxidant potential of $\alpha$-humulene was found poor as compared to $D$. pedicellatus and SPP oil demonstrating synergistic effect of other components present in oil.

\section{CONCLUSION}

The present investigation giving evident that proposed analytical GC-MS method can be used for quantitative analysis, quality control and standardization of various traditional Unani and Ayurvedic polyherbal formulations containing $D$. pedicellatus and or drugs containing $\alpha$-humulene as chief constituent. The present investigation has also provided evidence for antioxidant and antimicrobial potential of $\alpha$-humulene, $D$. pedicellatus oil and its traditional polyherbal formulation (SPP). Implementation of hyphenated techniques with pharmacokinetic studies of this traditional medicinal plant may guide to better understanding of its pharmacology and mechanism in near future. To support herbal drug investigation in upcoming and to expand activities, this study will help those who are involved in natural product research for discovery of herbal drug.

\section{ACKNOWLEDGMENT}

Authors are thankful to the CSIR, Center for Science and Industrial Research, Government of India, for their Fellowship.

\section{Conflict of interest statement}

The authors have no conflict of interest.

\section{REFERENCES}

1. Liu, Q.; Yao, H. Food Chem., 2007, 102, 732-737.

2. Iqbal, S.; Bhanger, M.I.; Anwar, F. LWT-Food Science Tech., 2007, 40, 361-367.

3. Chopra, R.N.; Nayer, S.L.; Chopra, I.C. 3rd ed.; Council of Scientific and Industrial Research: New Delhi, India., 1992, 7, 246.

4. Parekh, J.; Nair, R.; Chanda, S. Indian J. Pharmacol., 2005, 37, 408-409.

5. Pathak, V.P.; Saini, T.R.; Khanna, R.N. Phytochemistry., 1983, 22, 308-309.

6. Agarwal, V.S. Economic plants of India, Kailash Prakashan, Calcutta., 1986, 108.

7. Ambasta, S.P. The Useful Plants of India, Publications and Information Directorate,
CSIR, New Delhi., 1986, 171.

8. Kaur, G.; Lone, I.A.; Athar, M.; Alam, M.S. Chem. Biol. Interac., 2007, 165, 33-44.

9. Kapoor, S.L.; Kapoor, L.D. Sachitra Ayurveda., 1976, 28, 769-791.

10. Singh, A.P. Ethnobotanical Leaflets., 2007, 11, 73-75.

11. Anonymous; Qarabadeen Majeedi All India Unani Tibbi Conference Delhi; 9th Edition 1986.

12. Anonymous; The wealth of India second supplement series raw material., 2006, 3, 58.

13. Anonymous; The Unani Pharmacopoeia of India., 2007, 1, 58-59. 
14. Anonymous; The Unani Pharmacopoeia of India., 2007, 1, 91-92.

15. Ahmad, W.; Zaidi, S.M.A.; Mujeeb, M.; Ansari, S.H.; Ahmad, S. J. Chromatogr. Scien., 2014 52, 911-918.

16. Ahmad, W.; Zaidi, S.M.A.; Ahmad, S. Indian J. Tradi. Knowl., 2014, 13, 175-180.

17. $\mathrm{ICH}$.; Validation of Analytical Procedures: Methodology; ICH harmonized tripartite guidelines., 1997.

18. Sitohy, M.Z.; Mahgoub, S.A.; Osman, AO. Int. J. Food Microb., 2012, 154, 19-29.

19. Blois, M.S. Nature., 1998, 181, 1199-1200.

20. Hana, B.; Veronika, H.; Lenka, S.; Martin, A.; Iva, B. Curr. Topics Med. Chem., 2014, 14,
2478-2494.

21. Chaves, J.S.; Leal, P.C.; Pianowisky, L.; Calixto, J. B. Planta Medica., 2008, 74,16781683.

22. Shunying, V.; Yang, Y.; Huaidong, Y.; Yue, Y.; Guolin, Z. J. Ethano., 2005, 96, 151-158.

23. Atiqur, R.; Zakia, S.S.; Rashid, M.A.; Tanzina, P.; Shajia, A.; Khatun, M.K.; Sattar, M.A. Arabian J. Chem., 2011, doi; 10.1016/J. arabjc. 2011, 06, 003

24. Feng, Q.L.; Wu, J.; Chen, G.Q.; Cui, F.Z.; Kim, T.N.; Kim, J.O. J. Biomed. Mater. Res., 2002, 52, 662-668.

25. Gaunt, L.F.; Higgins, S.C.; Hughes, J.F. J. Appl. Microb., 2005, 99, 1324-1329. 